\title{
Teachers' work ability: a study of relationships between collective efficacy and self-efficacy beliefs
}

This article was published in the following Dove Press journal: Psychology Research and Behavior Management

\author{
Gloria Guidetti' \\ Sara Viotti' \\ Andreina Bruno ${ }^{2}$ \\ Daniela Converso' \\ 'Department of Psychology, University \\ of Turin, Turin, Italy; ${ }^{2}$ Department \\ of Education Science, University of \\ Genoa, Genoa, Italy
}

Introduction: Work ability constitutes one of the most studied well-being indicators related to work. Past research highlighted the relationship with work-related resources and demands, and personal resources. However, no studies highlight the role of collective and self-efficacy beliefs in sustaining work ability.

Purpose: The purpose of this study was to examine whether and by which mechanism work ability is linked with individual and collective efficacies in a sample of primary and middle school teachers.

Materials and methods: Using a dataset consisting of 415 primary and middle school Italian teachers, the analysis tested for the mediating role of self-efficacy between collective efficacy and work ability.

Results: Mediational analysis highlights that teachers' self-efficacy totally mediates the relationship between collective efficacy and perceived work ability.

Conclusion: Results of this study enhance the theoretical knowledge and empirical evidence regarding the link between teachers' collective efficacy and self-efficacy, giving further emphasis to the concept of collective efficacy in school contexts. Moreover, the results contribute to the study of well-being in the teaching profession, highlighting a process that sustains and promotes levels of work ability through both collective and personal resources.

Keywords: collective efficacy, mediation, self-efficacy, teachers, work ability

\section{Introduction}

It is well established that teaching is a stressful occupation ${ }^{1,2}$ due to societal, organizational, and interpersonal challenges that affect this profession. Most research in occupational health psychology investigated the negative aspects in the teaching profession that could affect health and well-being at work or that may foster malaise, such as burnout. ${ }^{3}$ On the other hand, fewer studies focused on factors that could sustain teachers' well-being at work. One of the most studied constructs in well-being literature is work ability which, according to Tuomi et al, ${ }^{4}$ describes the physical and intellectual resources on which workers rely to meet the demands posed by their work.

According to Tengland, ${ }^{5}$ work ability refers to the ability to carry out the work, which encompasses health-required status, occupational virtues, and competence for managing job tasks, and it is measured through the Work Ability Index (WAI). ${ }^{6}$ This tool consists of seven subscales regarding the subjective perception about the actual work ability (physical and mental resources) compared with the lifetime best, a subjective prognosis of work ability and mental resources, the work impairment, the number of
Correspondence: Sara Viotti Dipartimento di Psicologia, Università degli Studi di Torino, Via Verdi 8, 10124 Torino, Italy

Tel +390II 6702789

Email sara.viotti@unito.it 
diseases, and the absence from work due to disease. In this vein, work ability is a measure that is based on both burden of disease (given by number of diseases and the days of absence from work) and the individual perception of work ability. In this study, as previously done by other studies, ${ }^{7,8}$ we are interested to disentangle the health status from perceived work ability, which could be conceptualized as a subjective indicator of well-being.

As emerged from a systematic review, ${ }^{9}$ work ability has been mainly investigated in "aging" or "differences in ages" perspectives in relation to sociodemographic or life-style factors, work-related resources, and demands. In this perspective, prior research has outlined how physical and mental work demands (e.g., Ilmarinen et $\mathrm{al}^{10}$ ) on the one hand, and autonomy, supervisor support, and developmental opportunities on the other hand, constitute a pool of work-related factors that impact mainly on work ability. ${ }^{7,11}$

This trend is also reflected in studies focused on work ability in the teaching profession. ${ }^{8,12-16}$ Regarding specifically the Italian educational context, evidence suggests that work ability decreases as a function of age ${ }^{17}$ and that job resources differently impact on work ability across age cohorts. ${ }^{18}$ Otherwise, very few studies have analyzed the impact of psychological resources on work ability. Like job resources, psychological resources have a central role in dealing with stress as they contribute to inhibit dysfunctional responses to stressful situations. ${ }^{19}$ In this vein, as work ability represents a subjective indicator of well-being, it could be stated that psychological resources positively affect work ability.

Among research studies that first highlighted the role of psychological resources in relation to work ability, Airila et al, ${ }^{20}$ within the framework of the Job Demand-Resource model, ${ }^{21}$ evidenced that self-esteem is positively related with work ability via work engagement, whereas Sjogren-Ronka et $\mathrm{al}^{22}$ found a direct and positive relationship between selfconcept and work ability. Moreover, the study by McGonagle et $\mathrm{al}^{19}$ outlined that sense of control, which constitutes a relatively general and stable individual perception about one's own control over internal states, behaviors, and the environment, is an important source in sustaining work ability levels.

Even if these latter studies have outlined that various personal resources may play a central role in the promotion of work ability in different working populations, it is important to note that to date no scholars have considered the role exerted by self-efficacy. Self-efficacy is a personal resource that refers to a pattern of future-oriented beliefs about one's own capabilities in relation to specific tasks, and may determine how context-specific environmental opportunities or impediments are perceived. Moreover, the concept of self-efficacy differs from self-esteem and self-confidence which on the other hand represent positive self-evaluations of one's worth, significance, and ability as a person. ${ }^{23}$ Finally, differently from sense of control, self-efficacy is conceptualized as a context-specific and malleable belief about individual capabilities in facing external conditions. Furthermore, the differentiation between self-efficacy and sense of control has been clearly shown even within the teacher efficacy literature ${ }^{24}$ that developed measures based on Bandura's ${ }^{25}$ conceptualization of self-efficacy. ${ }^{26}$

As suggested by Bandura, ${ }^{25}$ teachers with low levels of self-efficacy tend to perceive their work environment as full of dangers or to emphasize the negative consequences of possible threats. These features may in turn contribute to undermine work ability. Moreover, regarding contextual resources, no studies took into account the role exerted by collective efficacy on work ability. As it will be further outlined, collective efficacy represents one of the main sources of self-efficacy. ${ }^{27}$ For this reason, we aim at examining the relationships between collective efficacy, self-efficacy, and work ability. In this view, understanding whether and by which mechanism work ability is linked with individual and collective efficacies may represent a powerful starting point to improve current knowledge regarding how to sustain work ability in the teaching profession.

\section{Teachers' self-efficacy}

The construct of self-efficacy in reference to the teaching profession has raised growing attention since the earliest studies of the RAND Corporation, ${ }^{28}$ which have highlighted how it is linked to teachers' professional behaviors and students' learning outcomes. ${ }^{29}$ Self-efficacy represents the individual teachers' beliefs in their own abilities to "plan, organize, and carry out activities required to attain given educational goals," (p. 612). ${ }^{26}$ Grounded into the human agency perspective, ${ }^{30,31}$ the concept of self-efficacy refers to a pattern of futureoriented beliefs that may influence not only behaviors and actions but also emotions, thoughts, and feelings, affecting the persistence and resilience in demanding situations. Stress or feelings of depression may be the result of self-inefficacy beliefs adopted in coping with environmental strains. ${ }^{25}$

As stated by Zee and Koomen, ${ }^{32}$ most studies on teachers' self-efficacy were developed in order to detect its effect on students' level outcomes or on academic adjustment, ${ }^{33,34}$ identifying as mediators in these relationships the ability to deal with instructional problems, ${ }^{35,36}$ to manage interpersonal dynamics with students, ${ }^{37,38}$ or to organize classroom processes. ${ }^{39,40}$ 
Although scholars' attention has been mainly paid to the relationship between teachers' self-efficacy and students' level outcomes, some studies highlighted how teachers' self-efficacy is a central personal resource to understand psychological well-being. Particularly, studies have pointed out that a high level of self-efficacy may reduce burnout levels, ${ }^{41-45}$ and enhance job satisfaction ${ }^{46}$ and commitment. ${ }^{47,48}$

Given its importance in sustaining well-being, it is also interesting to highlight possible factors capable of fostering self-efficacy. Moreover, a series of studies showed how environmental stressors in the educational context prevent teachers from sustaining their self-efficacy beliefs ${ }^{49-51}$ while others investigated the sources that enhance self-efficacy. ${ }^{52,53}$ A concept that may be considered as a resource of selfefficacy is collective efficacy.

\section{Teachers' collective efficacy}

In organizational contexts, such as the schools, the construct of efficacy might be investigated not only as a self-referent perception about own capabilities, but also as an emergent property of the (social) system as a whole, called "collective efficacy" (p. 467). ${ }^{25}$ Specifically referred to the educational context, it represents the teachers' beliefs that the school as a whole can implement and organize courses of actions affecting students and their levels of attainments. ${ }^{29}$ Even if it is an understudied construct, if compared with its "self" counterpart, collective efficacy is a powerful parameter to understand the quality of school life, also in terms of teachers' well-being. This tenet stems primarily from the fact that instructional reforms in Italy, since the late 1990s, have increasingly empowered single schools. In this reformed context, teachers are encouraged to work in a team, to share their goals and activities, thus grounding on these conjoint experiences the perception of their collective efficacy. ${ }^{54}$ Moreover, since the seminal work of Goddard et $\mathrm{al}^{55}$ on the predictive role of collective efficacy on students' academic achievement, many studies have been developed, which have extended the study to the relationships of collective efficacy with school climate and teachers' well-being. ${ }^{56-58}$ Moreover, as the collective efficacy is an emerging group-level property of shared actions separated and not reducible to the sum of self-efficacy beliefs,${ }^{59}$ it is possible to expect the existence of a relationship with self-efficacy as well, as emerged from different school-organizational studies. . $^{47,60-62}$

Theoretically speaking, it is possible to state that collective efficacy influences levels of self-efficacy. ${ }^{63}$ In line with Coleman's assumption on the role of social norms in affecting group behavior, ${ }^{64}$ goals and actions shared within a school act as source of normative pressure to which single teachers tend to conform. Moreover, this process is consistent with what has been proposed by Bandura's Social Cognitive Theory ${ }^{65}$ : the main sources of influence in the development of efficacy beliefs are social persuasion and mastery experience, which, at the school level, act as normative pressures. The high expectations set in a school with perceived high collective efficacy may encourage teachers to foster their persistence in front of the challenges posed by the school itself. Even if it is possible that comparison with a high efficacy environment could threaten some teachers' self-efficacy, past studies have highlighted that social comparison is more important for the development of self-concept than that of self-efficacy ${ }^{66,67}$ Conversely, a teacher's self-efficacy may decrease when, at faculty level, there are low expectations about future goal attainment, and colleagues or supervisors could not sustain the resilience, due to past failures, in front of demanding situations. As outlined from Skaalvik and Skaalvik, ${ }^{45}$ collective efficacy seems to be mostly correlated with supervisor's support, which is a source of the norms, values, and goals shared among the teachers of a faculty. In line with the above, Luthans et $\mathrm{al}^{68}$ asserted that a resourceful work environment, such as the one with high collective efficacy, sustains the employees' "psychological capital" (i.e., optimism, hope, resiliency, and efficacy development), thus activating personal resources that could in turn enhance psychological and organizational well-being.

From an empirical point of view, Goddard and Goddard ${ }^{27}$ examined this predictive role demonstrating how collective efficacy was the most powerful antecedent of self-efficacy over the effect of other school-level characteristics, such as socioeconomic status (SES), proportion minority, school size, and past achievement. Moreover, Lev and Koslowsky ${ }^{69}$ supported the same statement, highlighting that the relationship between teachers' collective and self efficacies is moderated by occupational level (managerial vs. non-managerial). Subsequently, this path has been extended in the study of teachers' level outcomes, primarily in the prediction of burnout and job satisfaction. Skaalvik and Skaalvik ${ }^{26}$ demonstrated that self-efficacy completely mediates the effect of collective efficacy on teachers' burnout, highlighting how this contextual resource lessens burnout symptoms through the improvement of self-efficacy.

Despite the theoretical ground ${ }^{63}$ which suggests the role played by collective efficacy as an antecedent of teachers' self-efficacy, the empirical evidence of the mediating role exerted by teachers' self-efficacy between teachers' collective efficacy and teachers' well-being is, however, still lacking investigation. 
Even if in the literature there are many studies that support the significance of the positive association between teachers' self-efficacy and some indicators of well-being (e.g., burnout, job satisfaction, and commitment), no evidence exists about its relationship with work ability. Finally, no studies examined the role exerted by collective efficacy in predicting work ability either directly or indirectly via self-efficacy.

Based on the theoretical and empirical background, this study has the aim to investigate a model of well-being at work, positing that teachers' collective efficacy acts as an environmental school resource in fostering teachers' selfefficacy beliefs which in turn enhance work ability.

The study hypotheses are:

H1: Teachers' collective efficacy positively relates to teachers' self-efficacy and work ability.

H2: Teachers' self-efficacy positively relates to perceived work ability.

H3: Teachers' self-efficacy mediates the relationship between teachers' collective efficacy and work ability.

\section{Materials and methods}

\section{Design and ethical considerations}

A cross-sectional design was used in order to collect data by means of a self-reported questionnaire. Data collection was conducted in a research program aimed at assessing the quality of teachers' working life. Before data collection, a series of meetings was conducted with the aim of sharing the objectives and the time plan of the research with both school administrators and teachers' representatives, who evaluated and authorized the use of data collection for scientific purposes.

Participants volunteered for the research without receiving any reward, signed the informed consent, and agreed to anonymously complete the questionnaire. The research conforms to the Declaration of Helsinki of 1995 (as revised in Edinburgh 2000), and all ethical guidelines were followed as required for conducting human research, including adherence to legal requirements of the study country. An additional ethical approval was not required since there was no treatment, including medical, invasive diagnostics or procedures causing psychological or social discomfort for the participants.

\section{Data collection}

After explaining the project's aims, a self-reported questionnaire was administered from January to March 2016.
Teachers at their own convenience returned the completed questionnaire anonymously in sealed boxes. Overall, the response rate was $33.93 \%$ (415 of the 1223 questionnaire were returned and considered valid for the analysis).

The majority of the participants were women (331, $79.8 \%$ ). The sample has a mean age of 45.11 years $(\mathrm{SD}=9.06) ; \min =23$ years; $\max =63$ years. Based on the grade level, the sample consisted of 232 primary school teachers $(55.9 \%)$ and $183(44.1 \%)$ middle school teachers.

\section{Instrumentation}

Teachers' Self-Efficacy was measured with the Perceived Personal Efficacy Scale in the school context. ${ }^{70}$ This onedimensional scale consisted of 12 items (seven-point Likert scale ranging from $1=$ totally disagree to $7=$ totally agree) aimed at capturing the teachers' self-efficacy in attaining educational and learning outcomes (e.g., "I can successfully cope with the difficulties in gaining learning attainments").

Teachers' Collective Efficacy was measured with the Perceived Collective Efficacy in school context. ${ }^{70}$ This onedimensional scale consisted of nine items (seven-point Likert scale ranging from $1=$ totally disagree to $7=$ totally agree). In line with the theoretical ground, collective efficacy does not derive from the sum of individual self-efficacy beliefs, but it captures otherwise the teachers' beliefs about the school's (as a whole) ability to successfully cope with critical situations (e.g., "Our school is able to fully achieve the objectives of school autonomy reforms").

\section{Work ability}

The authors employed a modified version of the Work Ability Index ${ }^{6}$ specifically aimed at assessing perceived work ability (WAI perceived), as suggested by McGonagle et al. ${ }^{7,71}$ It contained five items: 1 ) current work ability compared with lifetime best (range of the score 1-10); 2) work ability in relation to mental and physical demands (range of the score $2-10)$; 3) estimated work impairment due to diseases (range of the score 1-6); 4) self-prognosis of work ability for the next 2 years (range of the score 1-4 or 7); and 5) mental resources (range of the score 1-4).

\section{Control variables}

Literature findings highlight that age, gender, grade level (primary vs. middle school teachers), perceived health status, and psychological well-being (i.e., psychological exhaustion) may represent potential confounders in the relationships between efficacy and work ability. ${ }^{7-10}$ In order to collect data on psychological well-being at work, we 
measured psychological exhaustion using the Italian version of the Spanish Burnout Inventory ${ }^{62,73}$ consisting of four items (five-point Likert scale ranging from $0=$ Never to $4=$ Every Day; e.g., "I feel emotionally exhausted"). Perceived health status was measured with a single item: "How do you generally evaluate your own health status?" (Four-point scale ranging from: $1=$ excellent to $4=$ very poor). Low scores indicate positive evaluation of health; conversely, higher scores indicate poorer health status.

\section{Statistical analyses}

Statistical analyses were carried out using SPSS Package version 23. Means, standard deviation, and internal consistency of each variable under study were performed (Table 1). For each measure, items were summed and used for subsequent analyses.

Preacher and Hayes ${ }^{74}$ analytical approach was used in order to test the mediating role played by teachers' selfefficacy in the relationship between collective efficacy and work ability. This approach allowed us to test the indirect effect of a hypothesized antecedent variable on the outcome variable through a mediator. Moreover, through the evaluation of the total effect model (i.e., the effect of the antecedent variable on the outcome when the mediator is not included in the model), it evaluates if there is a total or a partial mediational effect. Furthermore, the bootstrap sampling procedure was used to generate a $95 \% \mathrm{CI}$ around the indirect effect to test

Table I Means, standard deviations, and Cronbach's alphas for each subscale

\begin{tabular}{lll}
\hline Subscale & M (SD) & $\boldsymbol{\alpha}$ \\
\hline Teachers' self-efficacy & $67.8(8.39)$ & 0.87 \\
Teachers' collective efficacy & $46.4(8.99)$ & 0.91 \\
WAl perceived & $30.49(3.58)$ & 0.62 \\
Psychological exhaustion & $7.48(3.14)$ & 0.81 \\
\hline
\end{tabular}

Abbreviation: WAI, work ability index. for its significance. When $95 \%$ CI did not include zero, the indirect effect is significant. Bootstrap confidence intervals were constructed using 5000 samples.

\section{Results Descriptive statistics and correlations}

Table 1 summarized means, standard deviations, and Cronbach's alpha for all the studied variables.

Pearson's correlations (Table 2) indicate that all the studied variables are significantly associated in the expected direction. As emerged, perceived work ability is positively and moderately correlated with both teachers' self and collective efficacies; furthermore, concerning the control variables, perceived work ability is negatively correlated with psychological exhaustion, perceived health status, and age. Finally, gender and grade level are not significantly correlated with perceived work ability; consequently, they have not been inserted into the mediational analysis.

\section{Mediational analysis}

Mediational analysis was then carried out in order to find out all the direct effects within the model and the indirect effect of collective efficacy on perceived work ability (controlling for age, perceived health status, and psychological exhaustion). Figure 1 represents the model of relationships between teachers' collective efficacy and self-efficacy beliefs and work ability, reporting unstandardized coefficients.

The estimates of path coefficients highlight that, on one hand, the total effect of collective efficacy on work ability is positive and significant on perceived work ability (path $c$, Figure $1 ; \mathrm{b}=0.47 ; p<0.001)$. Among the control variables, age $(b=-0.10 ; p<0.001)$, perceived health status $(b=-0.74$; $p<0.001)$, and psychological exhaustion $(\mathrm{b}=-0.33 ; p<0.001)$ were significantly associated with perceived work ability and in the expected direction. On the other hand, teachers' collective efficacy positively affects teachers' self-efficacy

Table 2 Pearson's correlations between all the studied variables

\begin{tabular}{|c|c|c|c|c|c|c|c|c|}
\hline & $\mathbf{I}$ & 2 & 3 & 4 & 5 & 6 & 7 & 8 \\
\hline I Teachers' self-efficacy & I & $0.42 * *$ & $0.34 * *$ & $-0.26 * *$ & $-0.09 *$ & 0.01 & 0.00 & 0.05 \\
\hline 2 Teachers' collective efficacy & & I & $0.21 * *$ & $-0.20 * *$ & $-0.09 *$ & 0.01 & 0.03 & 0.03 \\
\hline 3 WAI perceived & & & I & $-0.40 * *$ & $-0.40 * *$ & $-0.30 * *$ & 0.02 & 0.04 \\
\hline 4 Psychological exhaustion & & & & I & $0.3 I^{* *}$ & $0.09 *$ & -0.02 & $0.03^{* *}$ \\
\hline 5 Perceived health status & & & & & I & $0.26 * *$ & -0.03 & -0.10 \\
\hline $6 \mathrm{Age}$ & & & & & & I & -0.06 & $-0.09 *$ \\
\hline 7 Grade level & & & & & & & 1 & $0.23^{* *}$ \\
\hline 8 Gender ( $\mathrm{I}=$ male $)$ & & & & & & & & $\mathrm{I}$ \\
\hline
\end{tabular}

Note: ${ }^{*} p<0.05 ; * *_{p}<0.01$.

Abbreviation: WAl, work ability index. 


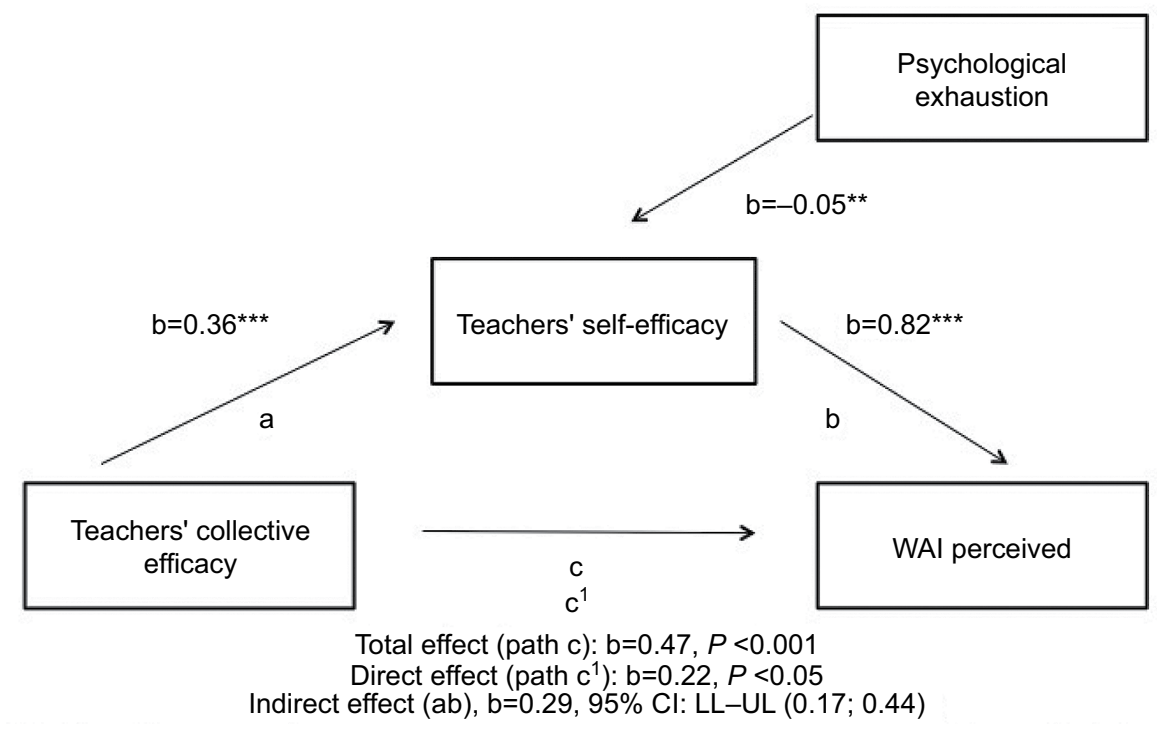

Figure I Model of relationships between teachers' collective efficacy and self-efficacy beliefs and work ability.

Notes: Covariates: age, gender, grade level, perceived health status, and psychological exhaustion. a=effect of teachers' collective efficacy on teachers' self-efficacy. b=effect of teachers' self-efficacy on work ability. c=total effect of teachers' collective efficacy on work ability. $c^{\prime}=$ direct effect of teachers' collective efficacy on work ability. Indirect effect (axb) of teachers' collective efficacy on work ability, through teachers' self-efficacy. ${ }^{* * *} p<0.00$ I; ${ }^{* *} p<0.0$ I.

Abbreviations: LL, lower level; UL, upper level; WAI, work ability index.

$(\mathrm{b}=0.36 ; p<0.001$; path a) and, among the control variables, only psychological exhaustion significantly relates with selfefficacy, exerting a negative effect $(\mathrm{b}=-0.05 ; p<0.01)$. These findings support H1.

Moreover, teachers' self-efficacy significantly and positively impacts on perceived work ability $(b=0.82, p<0.001$; path $b$ ), supporting H2. Finally, consistent with our hypothesis concerning the indirect effect $(\mathrm{a} \times \mathrm{b}$; i.e., the relationship between collective efficacy and work ability through the relationship with self-efficacy), the results evidence that self-efficacy significantly mediates the relationship between collective efficacy and perceived work ability $(b=0.29 ; 95 \%$ CI [LL-UL]: 0.17-0.44). These findings support H3, and, following Baron and Kenny, ${ }^{75}$ there is a full mediational effect of self-efficacy between collective efficacy and perceived work ability. In fact, as emerged from the analyses, the direct effect of teachers' collective efficacy is not significant $\left(b=0.22, p>0.05\right.$, ; path $\left.c^{1}\right)$. Among the control variables, age $(\mathrm{b}=-0.10 ; p<0.001)$, perceived health status $(\mathrm{b}=-0.70$; $p<0.001)$, and psychological exhaustion $(\mathrm{b}=-0.30 ; p<0.001)$ were significantly associated with perceived work ability and in the expected direction.

Since our data were cross-sectional, we also tested the hypothesized model against an alternative model that links teachers' self-efficacy with work ability via collective efficacy. Results showed that this alternative model was not supported, as the indirect effect was not found to be significant $(b=0.06 ; 95 \% \mathrm{CI}:-0.037,0.045)$. Therefore, additional support to our hypothesis on the mediating role of teachers' self-efficacy was found.

\section{Discussion}

This study gives important insights regarding how to sustain work ability in the teaching profession. Taken together, the results that emerged confirm the hypothesized model (Figure 1) in which perceived work ability of teachers constitutes the outcome of an efficacy process which starts from collective efficacy passing through self-efficacy beliefs.

Despite the emerging interest paid to collective efficacy in educational contexts, this is to date an understudied construct, specifically in the realm of teachers' well-being literature. This study has outlined, confirming previous theoretical assumptions ${ }^{25,63}$ and empirical findings, ${ }^{26,27}$ that collective efficacy in the teaching profession is related to self-efficacy. Despite the absence of longitudinal data not permitting to define a causality process between the variables under study, it is possible to note that collective efficacy beliefs act as powerful contextual resources in sustaining self-efficacy. An explanation of that relationship could be found within the Social Cognitive Theory, ${ }^{65}$ which has outlined that the main sources of self-efficacy are mastery experience and social/ verbal persuasion. Translated within the school context, these sources - that is, mastery faculty experience and instructions given by colleagues and superiors - could enhance and sustain efficacy beliefs in teachers. As Bandura ${ }^{65}$ has explained, through these sources the school setting defines goals and 
attainments, leading teachers to gain the expectations set by the environment.

Moreover, as emerged from the analyses, even if collective efficacy positively impacts on the final outcome, it disappears after including self-efficacy into the model. This means that self-efficacy totally mediates the impact of collective efficacy on perceived work ability, thus representing a fundamental psychological resource able to sustain perceived work ability among teachers. In this vein, the results of this study improve what has previously emerged from past research ${ }^{19,20,22}$ which underscored the importance of other personal resources, such as self-esteem, self-concept, and sense of control to understand perceived work ability and how to sustain it. Otherwise, differently from the extant literature, the present study takes into consideration a context-specific and more malleable personal resource, that is, teachers' self-efficacy. In this vein, our results give further insights regarding the role of personal resources in sustaining perceived work ability, as self-efficacy is more amenable to changes and improvements than more stable factors such as sense of control or self-esteem.

\section{Conclusion}

In the teaching profession, the possibility to maintain an adequate level of work ability, that is, the sum of mental and physical resources needed to manage the work tasks ${ }^{10}$ in an ever-changing environment, is a central point given the social relevance of this profession and its role played in the students' educational process. This study contributes to the work ability literature as it supports the importance to pay attention not only to sociodemographical or job-related features, but also to the personal features in promoting better levels of work ability. Through these results, we argue that supporting measures to work ability will take into account and assess the psychological resources, such as self-efficacy, on which the person can rely on.

Specifically, as self-efficacy affects the way of perceiving environmental opportunities or impediments, influencing goals, values, and behaviors, it is possible to state, in light of our results, that it could affect the way through which people evaluate their own ability at work: the more the teachers believe in their own capability, the more the resources will be devoted to gain professional tasks. This is of further importance, even for practical implications, because teachers' self-efficacy is a context-specific personal resource to leverage within the educational work environment. In this vein, this study highlights that the relationship between selfefficacy and work ability is in turn sustained by collective efficacy, which has important implications at both theoretical and practical levels. On one hand, it highlights that the role of self-efficacy in sustaining well-being in organizations is better explained by considering at the same time the role of collective efficacy. This may be particularly true in the case in which the organization is a school: in this context working in teams and sharing goals represent key aspects to sustain the quality of the teaching process. Indeed, for teachers, gaining insights into their practices and understanding learning environment conditions seem to lessen the risk of work overload and difficulties in managing learning process. ${ }^{76}$ Moreover, self and collective efficacies may allow teachers to provide students with significant learning experiences, thus stimulating students' perception of self-efficacy. ${ }^{77}$

Finally, on the practical side, with the aim to develop teachers' self-efficacy and consequently work ability, school administrators have to favor those processes that enhance or maintain collective efficacy such as sharing goals, values, and past success collectively, favoring the school's institutional commitment with other public or private institutions and with students' families.

\section{Limitations}

The present study has some limitations. First of all, the cross-sectional design does not permit to evaluate causal relationships between the variables. Longitudinal studies would explore cross-lagged associations between the constructs, examining also cyclic relationships and the impact that work ability could have on self-efficacy.

Another limitation concerns the measurement of self-efficacy beliefs. Though we used a well-established instrument to measure teachers' self-efficacy beliefs, ${ }^{70}$ this one-dimensional instrument does not permit to take into account the variety of tasks and demanding situations which teachers have to face. Future studies, using multidimensional measurements, may highlight different patterns between various aspects of self-efficacy and work ability.

Concerning measurement properties, perceived WAI did not reach quite satisfactory levels of reliability. This issue represents another limitation of the study, as it could undermine the accuracy of measurement effects. Regarding this issue, most of the past studies that evaluated work ability in the teaching profession ${ }^{13,14}$ did not report levels of reliability for this measure, except for the study of Viotti et $\mathrm{al}^{8}$ which reached adequate levels of reliability for perceived work ability in a sample of preschool teachers. Moreover, given the differences in measurement and sampling characteristics, future studies could shed more light on this issue, assessing 
perceived work ability in primary and middle school teachers to uncover comparable results.

Moreover, the sampling procedure was not randomized, and the sample is constituted of primary and middle Italian school teachers only. This implies that the results are not generalizable to other occupational sectors or also to other teachers' grade level. Moreover, it is possible that these results could change as a function of the culture (individualistic vs. collectivistic) ${ }^{78}$ especially regarding the relationship between collective and self-efficacy beliefs. Therefore, future studies could be implemented in order to detect possible cross-cultural differences.

Finally, as stated before, teachers' work ability has been principally evaluated in studies concerning the aging workforce. ${ }^{8,12-16}$ In this view, this model could be tested in older teachers' samples aiming to highlight its applicability also in sustaining active aging processes and favoring work ability in elderly teachers.

\section{Acknowledgment}

This work received a financial contribution from "Acamedia" (https://www.acamedia.unito.it/), in partnership with Collegio Carlo Alberto, Turin, Italy.

\section{Author contributions}

All authors contributed toward data analysis, drafting and revising the paper and agree to be accountable for all aspects of the work.

\section{Disclosure}

The authors report no conflicts of interest in this work.

\section{References}

1. Lodolo D'Oria V, Pecori Giraldi F, Vitello A, Vanoli C, Zeppegno P, Frigoli P.Burnout e patologia psichiatrica negli insegnanti [Burnout and psychiatric pathology in teachers]. 2006. Milano: Studio Getzemani. Available from: http://www.edscuola.it/archivio/psicologia/burnout. pdf.Accessed July, 16, 2017.

2. Stoeber J, Rennert D. Perfectionism in school teachers: relations with stress appraisals, coping styles, and burnout. Anxiety Stress Coping. 2008;21(1):37-53.

3. Kyriacou, C. Teacher stress. Directions for future research. Educ Rev. 2001;53(1):27-35.

4. Tuomi K, Eskelinen L, Toikkanen J, Jarvinen, E., Ilmarinen, J, Klockars M. Work load and individual factors affecting work ability among aging municipal employees. Scand J Work Environ Health. 1991;17(Suppl 1): 128-134.

5. Tengland PA. The concept of work ability. J Occup Rehabil. 2011;21(2): 275-285.

6. Tuomi K, Ilmarinen J, Jahkola A, Katajarinne L, Tulkki A. Work Ability Index. 2nded. Helsinki: Finnish Institute of Occupational Health; 1998.

7. McGonagle AK, Barnes-Farrell JL, Di Milia L, et al. Demands, resources, and work ability: a cross-national examination of health care workers. Eur J Work Organ Psychol. 2014;23(6):830-846.
8. Viotti S, Guidetti G, Loera B, Martini M, Sottimano I, Converso D. Stress, work ability, and an aging workforce: a study among women aged 50 and over. Int J Stress Manag. 2016;24(Supp1 1):98-121.

9. Van den Berg TIJ, Elders LAM, Zwart BCH, Burdorf A. The effects of work-related and individual factors on the work ability index: a systematic review. Occup Environ Med. 2009;66(4):211-220.

10. Ilmarinen J, Tuomi K, Seitsamo J. New dimensions of work ability. In: Costa G, Goedhart, WGA, Ilmarinen I, editors. Proceedings of the 2nd International Symposium on Work Ability;2004 Oct 18-20, Verona, IT. International Congress Series, Elsevier. 2005;1280:3-7.

11. Estryn-Behar M, Kreutz G, Le Nezet O, et al. Promotion of work ability among French health care workers-value of the Work Ability Index. In: Costa G, Goedhart, WGA, Ilmarinen I, editors. Proceedings of the 2nd International Symposium on Work Ability; 2004 Oct 18-20, Verona, IT. International Congress Series, Elsevier. 2005;1280:73-78.

12. Hakanen JJ, Bakker AB, Schaufeli WB. Burnout and work engagement among teachers. J Sch Psychol. 2006;43(6):495-513.

13. Marqueze EC, Voltz, GP, Borges FNS, Moreno, CRC. A 2-year follow up study of work ability among college educators. Appl Ergon. 2008;39(5):640-645.

14. Kinnuen U, Parkatti T, Rasku A. Occupational wellbeing among ageing teachers in Finland. Scand J Educ Res. 1999;38(3-4):315-332.

15. Seibt R, Spitzer S, Blank M, Scheuch K. Predictors of work ability in occupations with psychological stress. J Public Health. 2009;17(1):9-18.

16. Vedovato Giovanelli T, Monteiro I. Health conditions and factors related to the work ability of teachers. Ind Health. 2014;52(2):121-128.

17. Converso D, Viotti S, Sottimano I, Cascio V, Guidetti G. Capacità lavorativa, salute psico-fisica, burnout ed età, tra insegnanti d'infanzia ed educatori di asilo nido: uno studio trasversale [Work ability, psychophysical health, burnout, and age among nursery school and kindergarten teachers: a cross-sectional study]. Med Lav. 2015;106:91-108.

18. Sottimano I, Viotti S, Guidetti G, Converso D. Protective factors for work ability in preschool teachers. Occup Med. 2017;67(4):301-304.

19. McGonagle AK, Fisher GG, Barnes-Farrell JL, Grosh JW. Individual and work factors related to work ability and labor force outcomes. J Appl Psychol.2015;100(2):376-398.

20. Airila A, Hakanen JJ, Schaufeli WB, Luukkonen R, Punakallio A, Lusa S. Are job and personal resources associated with work ability 10 years later? The mediating role of work engagement. Work Stress.2014;28(1):87-105.

21. Demerouti E, Bakker AB, Nachreiner F, Schaufeli WB. The job demandsresources model of burnout. J Appl Psychol. 2001;86(3):499-512.

22. Sjogren-Ronka T, Ojanen MT, Leskinen EK, Mustalampi ST, Mälkiä, EA. Physical and psychosocial prerequisites of functioning in relation to work ability and general subjective well-being among office workers. Scand J Work Environ Health. 2002;28(3):184-190.

23. Janssen PPM, Schaufeli W B, Houkes I. Work-related and individual determinants of the three burnout dimensions. Work Stress. 1999;13(1):74-86.

24. Gibson S, Dembo M. Teacher efficacy: a construct validation. J Educ Psychol. 1984;76(4):569-582.

25. Bandura, A. Self-Efficacy: The Exercise of Control. New York, NY: Freeman; 1997.

26. Skaalvik EM, Skaalvik S. Dimensions of teacher self-efficacy and relations with strain factors, perceived collective teacher efficacy, and teacher burnout. J Educ Psychol. 2007;99(3):611-625.

27. Goddard RD, Goddard Y. A multilevel analysis of the relationship between teacher and collective efficacy in urban schools. Teach Teach Educ. 2001;17(7):807-818.

28. Armor D, Conroy-Oseguera P, Cox M, et al. Analysis of the School Preferred Reading Programs in Selected Los Angeles Minority Schools.1976. Rep. No. R-2007-LAUSD.Santa Monica, CA: Rand Corporation.

29. Tschannen-Moran M, Woolfolk Hoy A, Hoy WK. Teacher efficacy: its meaning and measure. Rev Educ Res. 1998;68(2):202-248.

30. Rotter JB. Generalized expectancies for internal versus external control of reinforcement. Psychol Monogr. 1996;80(1):1-28. 
31. Bandura, A. Self-efficacy: toward a unifying theory of behavioral change. Psychol Rev. 1977;84(2):191-215.

32. Zee M, Koomen HMY. Teacher self-efficacy and its effect on classroom processes, student academic adjustment, and teacher well-being: a synthesis of 40 years of research. Rev Educ Res. 2016;86(4):981-1015.

33. Caprara GV, Barbaranelli C, Steca P, Malone PS. Teachers' self-efficacy beliefs as determinants of job satisfaction and students' academic achievement: a study at the school level. J Sch Psychol. 2006;44(6) 473-490.

34. Reyes MR, Brackett MA, Rivers SE, White M, Salovey P. Classroom emotional climate, student engagement, and academic achievement. J Educ Psychol. 2012;104(3):700-712.

35. Martin N K, Sass DA, Schmitt TA. Teacher efficacy in student engagement, instructional management, student stressors, and burnout: a theoretical model using in-class variables to predict teachers' intentto-leave. Teach Teach Educ. 2012;28(4):546-559.

36. Künsting J, Neuber V, Lipowsky F. Teacher self-efficacy as a long-term predictor of instructional quality in the classroom. Eur J Psychol Educ. 2016;31(3):299-322.

37. De Jong R, Mainhard T, van Tartwijk J, Veldman L, Verloop N, Wubbels T. How preservice teachers personality traits, self-efficacy, and discipline strategies contribute to the teacher-student relationship. Br J Educ Psychol. 2014;84(2):294-310.

38. Mashburn AJ, Hamre BK, Downer JT, Pianta RC. Teacher and classroom characteristics associated with teachers' ratings of pre-kindergartners' relationships and behavior. J Psychoeduc Assess. 2006;24(4): 367-380.

39. Almog O, Shechtman, Z. Teachers' democratic and efficacy beliefs and styles of coping with behavioural problems of pupils with special needs. Eur J Spec Needs Educ. 2007;22(2):115-129.

40. Malinen O, Savolainen H, Xu J. Beijing in-service teachers' selfefficacy and attitudes towards inclusive education. Teach Teach Educ. 2012;2(4):526-534.

41. Avanzi L, Miglioretti M, Valsco V, et al. Cross-validation of the Norwegian teacher's self-efficacy scale. Teach Teach Educ. 2013;31(1):69-78.

42. Brouwers A, Tomic W. A longitudinal study of teacher burnout and perceived self-efficacy in classroom management. Teach Teach Educ. 2000;16(2):239-253

43. Fives H, Hamman D, Olivares A. Does burnout begin with studentteaching? Analyzing efficacy, burnout, and support during the studentteaching semester. Teach Teach Educ. 2007;23(6):916-934.

44. Schwarzer R, Hallum S. Perceived Teacher self-efficacy as predictor of job stress and burnout: mediation analyses. J Appl Psychol Int Rev. 2008;57(Suppl):152-171.

45. Skaalvik EM, Skaalvik S. Teacher self-efficacy and teacher burnout: a study of relations. Teach Teach Educ. 2010;26(4):1059-1069.

46. Skaalvik EM, Skaalvik S. Teacher self-efficacy and perceived autonomy: relations with teacher engagement, job satisfaction, and emotional exhaustion. Psychol Rep. 2014;114(1):68-77.

47. Ware H, Kitsantas A. Teacher and collective efficacy beliefs as predictors of professional commitment. J Educ Res. 2007;100(5):303-310.

48. Klassen RM, Chiu MM. The occupational commitment and intention to quit of practicing and pre-service teachers: influence of selfefficacy, job stress, and teaching context. Contemp Educ Psychol. 2011;36(2):114-129.

49. Collie RJ, Shapka JD, Perry NE. School climate and social-emotional learning: predicting teacher stress, job satisfaction, and teaching efficacy. J Educ Psychol. 2012;104(4):1189-1204.

50. Klassen R, Wilson E, Siu AFY, et al. Preservice teachers' work stress, self-efficacy, and occupational commitment in four countries. Eur $J$ Psychol Educ. 2013;28(4):1289-1309.

51. Skaalvik EM, Skaalvik S. Teacher stress and teacher self-efficacy as predictors of engagement, emotional exhaustion, and motivation to leave the teaching profession. Creat Educ. 2016;7(13):1785-1799.

52. De Neve D, Devos G, Tuytens M. The importance of job resources and self-efficacy for beginning teachers' professional learning in differentiated instruction. Teach Teach Educ. 2015;47:30-41.
53. Tschannen-Moran M, Woolfolk Hoy A. The differential antecedents of self-efficacy beliefs of novice and experienced teachers. Teach Teach Educ. 2007;23(6):944-956.

54. Parker K, Hannah E, Topping KJ. Collective teacher efficacy, pupil attainment and socio-economic status in primary school. Improving Schools. 2006;9(2):111-129.

55. Goddard RD, Hoy AK, Woolfolk-Hoy A. Collective teacher efficacy: its meaning, measure, and impact on student achievement. Am J Educ Res. 2000;37(2):479-507.

56. Klassen RM, Usher EL, Bong M. Teachers' collective efficacy, job satisfaction, and job stress in cross-cultural context. J Exp Educ. 2010:78(4):464-486.

57. Lim S, Eo S. The mediating roles of collective teacher efficacy in the relations of teachers' perceptions of school organizational climate to their burnout. Teach Teach Educ. 2014;44:138-147.

58. Malinen P-O, Savolainen, H. The effect of perceived school climate and teacher efficacy in behavior management on job satisfaction and burnout: a longitudinal study. Teach Teach Educ. 2016;60:144-152.

59. Bandura, A. Social cognitive theory: an agentic perspective. Annu Rev Psychol. 2001; 52:1-26.

60. Caprara GV, Barbaranelli C, Borgogni L, Steca P. Efficacy beliefs as determinants of teachers' job satisfaction. J Educ Psychol. 2003;95(4): 821-832.

61. Stephanou G, Gkavras G, Doulkeridou M. The role of teachers' self and collective-efficacy beliefs on their job satisfaction and experienced emotions in school. Psychology. 2013;4(3A):268-278.

62. Viel-Ruma H, Houchins D, Jolivette K, Benson G. Efficacy beliefs of special educators: the relationships among collective efficacy, teacher self-efficacy, and job satisfaction. Teach Educ Spec Educ. 2010;33(3):225-233.

63. Goddard RD, Hoy WK, Woolfolk Hoy A. Collective efficacy beliefs: theoretical developments, empirical evidence, and future directions. Educ Res. 2004;33(3):3-13.

64. Coleman, J. S. Norms as social capital. In: Radnittzky G, Bernholz P, editors. Economic Imperialism: The Economic Approach Applied Outside the Field of Economics. New York, NY: Paragon House Publishers; 1987.

65. Bandura, A. Social Foundations of Thoughts and Action. A Social Cognitive Theory. Englewood Cliffs, NJ: Prentice-Hall; 1976.

66. Marsh HW, Walker R, Debus R. Subject specific components of academic self concept and self efficacy. Contemp Educ Psychol. 1991;16(4):331-345.

67. Skaalvik EM, Bong M. Self-concept and self-efficacy revisited: a few notable differences and important similarities. In: Marsh HW, Craven RG, McInerney DM. editors. International Advances in Self Research. Greenwich: Information Age; 2003:29.

68. Luthans F, Avey JB, Avolio BJ, Norma SM, Coms GM. Psychological capital development: toward a micro-intervention. J Organ Behav. 2006;27(3):387-393.

69. Lev S, Koslowsky M. Moderating the collective and self-efficacy relationship. J Educ Adm Hist. 2004;47(4):452-462.

70. Borgogni L, Petitta L, Steca P. Efficacia personale e collettiva nei contesti organizzativi [Personal efficacy and Collective efficacy in organizational contexts]. In: Caprara GV editor. La valutazione dell'autoefficacia [The Assessment of Self-Efficacy]. Trento IT: Erickson; 2001:265.

71. McGonagle AK, Fisher GG, Barnes-Farrell JL, Grosch JW. Individual and work factors related to perceived work ability and labor force outcomes. J Appl Psychol. 2015;100(2):376-398.

72. Viotti S, Gil-Monte P, Converso, D. Toward validating the Italian version of the "Spanish Burnout Inventory": a preliminary study on an Italian nursing sample. Rev Esc Enferm USP.2015;49(5):819-825.

73. Viotti S, Guidetti G, Gil-Monte P, Converso, D. La misurazione del burnout nei contesti sanitari: validità di costrutto e invarianza fattoriale della versione italiana dello Spanish Burnout Inventory (SBI-Ita). [Measuring burnout among health-care workers: construct validity and factorial invariance of the Italian version of the Spanish Burnout Inventory (SBI-Ita). Psicologiadella Salute. 2017;1(1):123-144. 
74. Preacher KJ, Heyes AF. SPSS and SAS procedures for estimating indirect effects in simple mediation models. Behav Res Method Instrum Comput. 2004;36(4):717-731.

75. Baron RM, Kenny DA. The moderator-mediator variable distinction in social psychological research: conceptual, strategic and statistical consideration. J Pers Soc Psychol. 1986;51(6):11731182.
76. Bruno A, Dell'Aversana G. Reflective Practicum in higher education: the influence of the learning environment on the quality of learning. Assess Eval High Educ. 2018;43(3):345-358.

77. Jungert T, Rosander M. Self-efficacy and strategies to influence the study environment. Teach High Educ. 2010;16(6):647-659.

78. Triandis HC. Individualism and Collectivism. Boulder, CO: Westview Press; 1995.

\section{Publish your work in this journal}

Psychology Research and Behavior Management is an international, peerreviewed, open access journal focusing on the science of psychology and its application in behavior management to develop improved outcomes in the clinical, educational, sports and business arenas. Specific topics covered in the journal include: Neuroscience, memory and decision making; Behavior modification and management; Clinical applications; Business and sports performance management; Social and developmental studies; Animal studies. The manuscript management system is completely online and includes a very quick and fair peer-review system, which is all easy to use. Visit http://www dovepress.com/testimonials.php to read real quotes from published authors. 